\title{
Arctic Clouds and Surface Radiation - a critical comparison of satellite retrievals and the ERA-Interim reanalysis
}

\author{
M. Zygmuntowska ${ }^{1,2}$, T. Mauritsen ${ }^{1}$, J. Quaas ${ }^{1,3}$, and L. Kaleschke ${ }^{4}$ \\ ${ }^{1}$ Max Planck Institute for Meteorology, Hamburg, Germany \\ ${ }^{2}$ Nansen Environmental and Remote Sensing Center, Bergen, Norway \\ ${ }^{3}$ Leipzig Institute for Meteorology, University of Leipzig, Germany \\ ${ }^{4}$ Institute of Oceanography, University of Hamburg, Germany
}

Correspondence to: M. Zygmuntowska (marta.zygmuntowska@nersc.no)

Received: 6 September 2011 - Published in Atmos. Chem. Phys. Discuss.: 1 December 2011

Revised: 18 July 2012 - Accepted: 20 July 2012 - Published: 27 July 2012

\begin{abstract}
Clouds regulate the Earth's radiation budget, both by reflecting part of the incoming sunlight leading to cooling and by absorbing and emitting infrared radiation which tends to have a warming effect. Globally averaged, at the top of the atmosphere the cloud radiative effect is to cool the climate, while at the Arctic surface, clouds are thought to be warming. Here we compare a passive instrument, the AVHRR-based retrieval from CM-SAF, with recently launched active instruments onboard CloudSat and CALIPSO and the widely used ERA-Interim reanalysis. We find that in particular in winter months the three data sets differ significantly. While passive satellite instruments have serious difficulties, detecting only half the cloudiness of the modeled clouds in the reanalysis, the active instruments are in between. In summer, the two satellite products agree having monthly means of 70 80 percent, but the reanalysis are approximately ten percent higher. The monthly mean long- and shortwave components of the surface cloud radiative effect obtained from the ERAInterim reanalysis are about twice that calculated on the basis of CloudSat's radar-only retrievals, while ground based measurements from SHEBA are in between. We discuss these differences in terms of instrument-, retrieval- and reanalysis characteristics, which differ substantially between the analyzed datasets.
\end{abstract}

\section{Introduction}

The Earth's climate is observed to change since the beginning of the 20th century. This climate change is more pro- nounced in the high latitude Arctic region than in the rest of the world (ACIA, 2005; Serreze and Francis, 2006; Solomon et al., 2007). This Arctic amplification of climate change can be identified by rising surface temperatures and by the rapid decline of the Arctic sea ice extent, which have been attributed to anthropogenic greenhouse gas forcing (Gillett et al., 2008; Min et al., 2008). However, it is generally recognized that considerable natural variability prevails in the Arctic (Serreze et al., 2007). The sea ice decline culminated in 2007 when the Arctic sea ice reached a September minimum extent of $4.3 \cdot 10^{6} \mathrm{~km}^{2}$ - a value more than forty percent below that at the beginning of the satellite-era in 1979 (Stroeve et al., 2007). The underlying mechanisms making the Arctic climate both more sensitive and variable than the rest of the globe are not well understood. Suggestions include regionally enhanced warming mechanisms, including the surface albedo changes arising from melting snow and ice in a warming climate (Manabe and Wetherald, 1975), water vapor (Manabe and Wetherald, 1980), the vertical stratification trapping heat near the surface (Manabe and Wetherald, 1975; Held, 1979), along with shifts in the atmosphere and ocean circulations leading to more transport of heat and moisture into the Arctic (Manabe and Wetherald, 1975; Holland and Bitz, 2003; Graversen et al., 2008).

Clouds play a central, yet complex role in the Arctic climate system. Clouds both cool by reflecting incoming sunlight back to space, and warm by absorbing outgoing infrared radiation and typically emit at a lower temperature than the surface. We define the cloud radiative effect (CRE) as the difference between the actual net radiative fluxes and what they 
would have been in an otherwise identical, but cloud-free atmosphere. Globally, at the top of the atmosphere clouds cool the Earth system (Schneider, 1972; Ramanathan et al., 1989), whereas at the surface in the Arctic clouds have a predominantly warming effect. (Walsh and Chapman, 1998; Intrieri et al., 2002a). In the Arctic, the dry background atmosphere enhances the cloud longwave warming effect, while the high surface albedo over snow and ice combined with the high solar zenith angles acts to reduce the cloud shortwave cooling effect (Curry and Herman, 1985; Curry et al., 1996). The prevalent Arctic inversion (Kahl et al., 1996) further complicates estimates of the longwave radiative effect because clouds might occasionally be warmer than the surface. The spread in cloud fields in global climate models is large, including the phase of the annual cycle of total cloud cover, with monthly means ranging from 35 to 95 percent, vertically integrated liquid water paths varying by more than an order of magnitude and widely disparate cloud radiative effects, for example varying from $-30 \mathrm{~W} \mathrm{~m}^{-2}$ to $+10 \mathrm{~W} \mathrm{~m}^{-2}$ in summer months (Karlsson and Svensson, 2011).

Early studies suggested that clouds add to Arctic climate sensitivity and variability by constituting a regionally positive feedback mechanism through enhanced cloudiness in a warming climate (Schneider, 1972; Ramanathan, 1977; Wetherald and Manabe, 1988). However, the many possible interactions of clouds with the underlying surface seriously complicate these estimates, as observations and models suggest increased cloudiness as a response to sea-ice loss (Abbot et al., 2009; Cuzzone and Vavrus, 2011; Vavrus et al., 2011), which may lead to either cooling or warming due to the decreased surface albedo and depending on seasonality. In general a seasonal variation has been found in this cloud response (Kay and Gettelman, 2009), which can be explained by near surface static stability and air-sea temperature gradients. Other studies imply in turn that the recent decline in sea ice extent is associated with a decrease in cloudiness (Kay et al., 2008). Additionally, several studies indicate that aerosol influences on cloud emissivity are particularly strong in the Arctic, leading to aerosol indirect effects which are regionally warming, as opposed to the global cooling effect (Garrett and Zhao, 2006; Lubin and Vogelmann, 2006; Mauritsen et al., 2011). To better understand the cloud radiative effect, cloud climate feedbacks and the cloud-sea-ice interactions, it is necessary to have precise information about not only cloud properties and occurrence, but also the environment in which they are embedded.

Clouds are objects with poorly defined boundaries, partly because they consist of droplets and ice particles dispersed in a turbulent media, partly because of their ability to form and evaporate depending on the local super- or subsaturation. It is difficult to tell where they begin and where they end, and therefore we rather tend to define them in terms of their radiative properties. For example, the human observer will require them to be visible; detectable by the human eye under prevailing light conditions. Remote sensors may use certain characteristics of visible and infrared emission, while lidars and radars operationally define thresholds in the detected returned signal. Naturally, the results will depend on the characteristics of the sensor, the cloud detection threshold combined with the targeted cloud itself.

The Arctic is known to be a cloudy region. Over the Arctic Ocean, mid- and high-level clouds are believed to be mainly associated with frontal systems and they vary seasonally in amount (Curry and Herman, 1985). In a stable atmosphere, which is prevalent in the central Arctic, clouds can form when relatively warm and moist air is advected into the polar regions. Over the cooler surface the air cools and condensation occurs to form stratus or stratocumulus clouds (Herman and Goody, 1976; Curry, 1983). These types of clouds tend to be shallow, from a few hundred meters up to one to two kilometers. Under unstable atmospheric conditions low-level cumulus clouds can form when air is advected over relatively warm surfaces. In wintertime this can be observed over open leads, or cracks in the sea ice, and throughout the year during cold-air outbreaks from the pack-ice to the open ocean (Curry et al., 1996). Clouds tend to extend deeper under unstable conditions.

Previous studies based on passive sensors and human observers found a total cloud cover of up to 90-95 percent in summer months and values around 50 percent in winter, with sharp transition seasons in April and October (Huschke, 1969; Schweiger and Key, 1992; Eastman and Warren, 2010). The total cloud cover was found to be mainly dominated by semi-permanent low-level clouds, while midand high-level clouds show a low amplitude in the annual cycle. However, since these previous studies have relied on either human observations, or passive satellite instruments it remains an open question to which extent wintertime cloud observations and the observed annual cycle in cloudiness is caused by the lack of sunlight in winter causing a poor detection of clouds, confirmed by active sensors showing around 70 percent cover in winter (Intrieri et al., 2002a). Further, clouds in the Arctic are frequently optically thin (Shupe and Intrieri, 2004; Sedlar et al., 2010), occasionally sub-visible due to the lack of aerosol upon which cloud droplets can form, making detection by any means particularly difficult even in summer (Mauritsen et al., 2011).

The scientific community therefore had high expectations on improving the situation when NASA launched two new active satellites in 2007, carrying a millimeter wavelength cloud radar, CloudSat, and a dual-channel lidar, CALIPSO (Stephens et al., 2002). These active sensors are less sensitive to environmental conditions, promise low detection limits, and require fewer assumptions in the retrievals of cloud properties, than do passive instruments. However, even these instruments do have their limitations, as CloudSat is unable to detect optically thin clouds and retrievals are hampered by ground clutter at levels near the surface, while CALIPSO is attenuated if exposed to scenes with optically thick clouds. Beside these limitations in the retrieval techniques, not all 


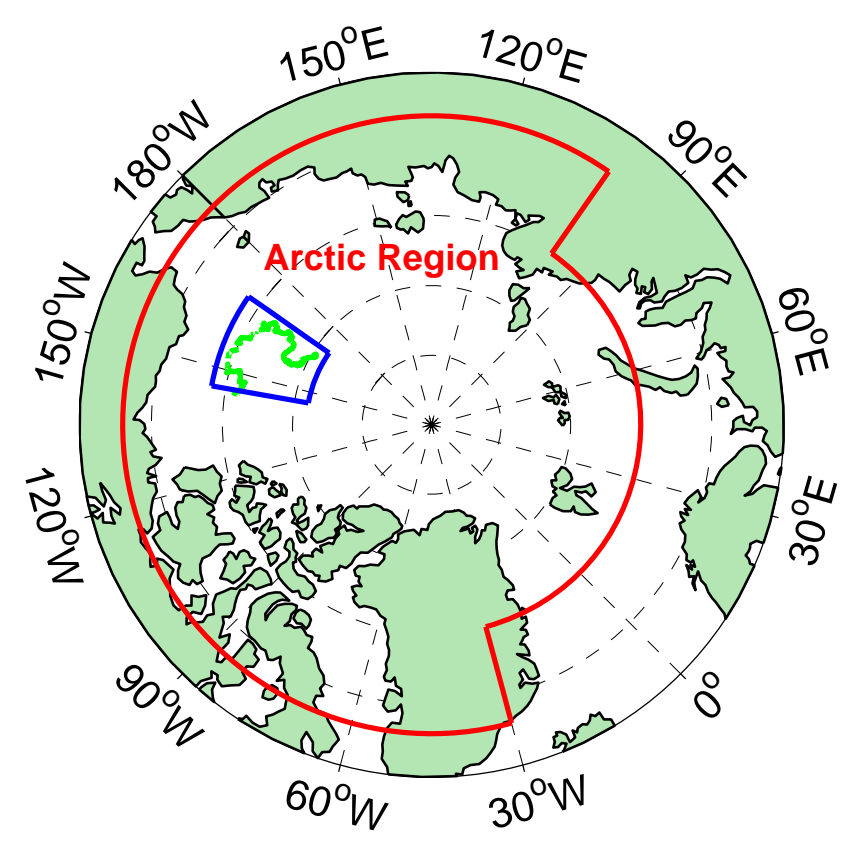

Fig. 1. Arctic Ocean as defined in this study. Ocean grid-points in the area enclosed by the red line are considered for the analysis. The green trajectory shows the drifting ice floe used for the SHEBA campaign and the area enclosed by the blue line is used for comparison with ERA-Interim.

the necessary processing steps are incorporated in the current data sets such as the implementation of multiple scattering, changing albedo or variable solar zenith angle.

In this study the main focus is to advance knowledge of cloud occurrence and the radiative budget over the Arctic Ocean on the basis of new and widely used datasets and the differences between them. Differences may not only result from different instruments and retrieval techniques but from something as fundamental as the definition of clouds and cloud radiative properties. Herein we first evaluate climatologies based on CloudSat and CALIPSO, new retrievals from passive instrument AVHRR satellites and from the ERA-Interim reanalysis. Further the components of the cloud radiative effect estimated from CloudSat and ERA-Interim are compared. Ground-based observations from the SHEBA project (1997-98) are used to estimate the possible impacts of instrumental shortcomings and reanalysis biases on the results.

\section{Data and methods}

In this study the Arctic is defined as the area north of $68^{\circ} \mathrm{N}$, excluding the area between $30^{\circ} \mathrm{E}$ and $100^{\circ} \mathrm{W}$ south of $75^{\circ} \mathrm{N}$ as it is dominated by the inflow of warmer water masses which differ substantially from the rest of the Arctic Ocean (Fig. 1). We interpolate and aggregate all our statistical quantities to a common polar stereographic grid with a resolution of $200 \mathrm{~km}$ to facilitate the intercomparison. The grid resolution was chosen to minimize sampling noise, while retaining spatial information. Only data over the oceans and sea ice are analyzed.

CloudSat and CALIPSO were launched in April 2006 and fly in a tight orbital coordination so that they image the same atmospheric volume within short time. CloudSat is carrying the Cloud Profiling Radar (CPR) and CALIPSO is carrying the Cloud-Aerosol-Lidar with Orthogonal Polarization (CALIOP). The wavelength of the radar pulse is $3 \mathrm{~mm}$ and the small Rayleigh cross section allows the pulse to penetrate deep into the atmosphere and detect multiple layers of clouds. The Cloud-Aerosol-Lidar in turn with wavelengths of $532 \mathrm{~nm}$ and $1064 \mathrm{~nm}$ is able to detect clouds which are thin and dominated by small particles. Both instruments are active sensors, measuring the energy backscattered from the clouds, and therefore, in contrast to passive retrievals, cloud detection is not affected by the frequent temperature inversions and difficult light conditions in the Arctic region. Nonetheless it is a known issue that clouds at low altitudes below $1000 \mathrm{~m}$ are often not identified and below $500 \mathrm{~m}$ almost no clouds are detected. Here the radar signal is contaminated by surface clutter from the reflected radar beam, while the lidar pulse is frequently attenuated by thick overlaying clouds (Mace, 2003; Winker et al., 2007; Stephens et al., 2008).

A combined radar-lidar cloud mask has been obtained from the 2B-GEOPROF-LIDAR data set. The 2BGEOPROF-LIDAR data set is a level 2 product, which combines information from CloudSat and CALIPSO level 1 data sets and auxiliary data to retrieve information about cloud occurrence (Mace, 2008; Marchand et al., 2008). Auxiliary data is obtained from the European Centre for Medium-Range Weather Forecasts (ECMWF) and contains state variables such as pressure, temperature, and humidity (Partain, 2004). MODIS auxiliary data provides radiance and cloud mask data from the MODIS satellite that overlap each CloudSat CPR footprint (Partain, 2004). The merged 2B-GEOPROFLIDAR data set provides a hydrometeor fraction for every vertical level and up to five cloud tops and bases for every profile. In the present study, information about cloud tops are used to calculate a combined cloud mask which has been interpolated to the common polar stereographic grid. Low level clouds are defined as clouds with a cloud top below $3000 \mathrm{~m}$. To analyze the influence of clouds on the radiation budget, the 2B-FLXHR data set is used, another level 2 Standard Data Product provided by CloudSat (L'Ecuyer, 2007; L'Ecuyer et al., 2008). It provides down- and upwelling radiative flux estimates for every profile. Calculations are based on atmospheric transmittance and reflectivity from CloudSat, and information about humidity and temperature are obtained from ECMWF. No information from CALIPSO is used when calculating fluxes.

Over the Arctic region the 2B-FLXHR dataset is biased as no information about the surface albedo alterations due to sea ice has been included. Instead the albedo is assumed to equal 


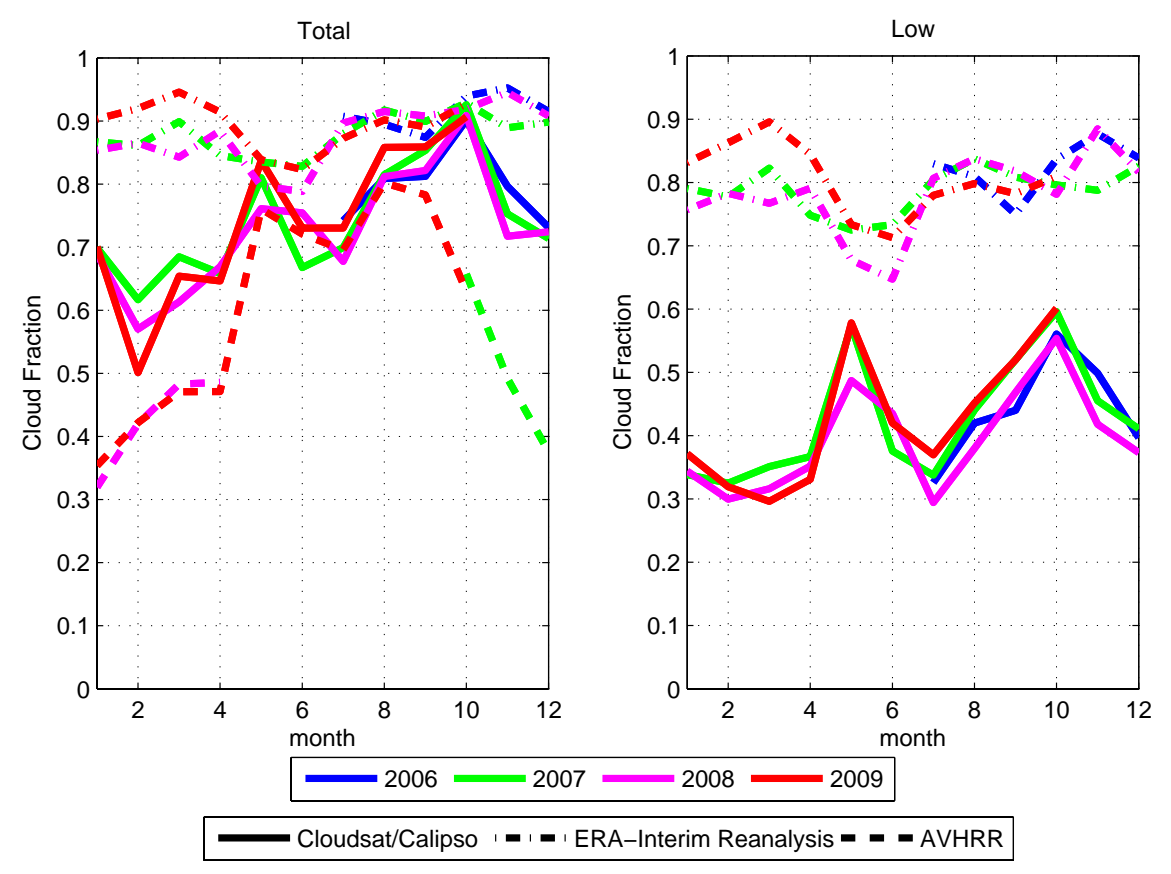

Fig. 2. Annual cycles of total- and low-level cloud fraction from 2006 to 2009 for the Arctic Ocean as derived from CloudSat/CALIPSO, ERA-Interim and an AVHRR-based retrieval from CM-SAF. For low-level clouds no data is available from AVHRR.

that of an open ocean. To improve the estimation of radiative fluxes over the arctic ocean, values for upwelling fluxes are recalculated in the present study. Based on retrievals for sea ice concentration from the SSM/I (Kaleschke et al., 2001) the albedo of all grid cells with a concentration of sea ice above 15 percent is set to a value of 45 and 75 percent, respectively, to get an estimate of the upper and lower bounds of net radiative shortwave fluxes. Changes in surface longwave fluxes from the ocean are not taken into account as the surface temperature is taken from ECMWF and emissivity is assumed unity. Multiple scattering between the bright sea ice surface and clouds are neither considered.

The Advanced Very High Resolution Radiometer (AVHRR) measures the irradiance from the Earth in 6 spectral bands from visible $(\approx 0.58 \mu \mathrm{m})$ to far-infrared $(\approx 12.5 \mu \mathrm{m})$, and has been in use since the 1970 s providing some potential for studying longterm changes. Here data processed by EUMETSAT's Satellite Application Facility on Climate Monitoring (CM-SAF) has been used. The underlying algorithm is the NWCSAF PPS which uses dynamic thresholds for various spectral and texture features to distinguish between several cloud types (Dybbroe et al., 2005). Herein, however, only monthly averaged values for the fractional cloud cover are analyzed what can be seen as the percentage of cloud contaminated pixels (Kaspar et al., 2009). Values are provided on a Lagrangian grid with a spatial resolution of $15 \mathrm{~km} \times 15 \mathrm{~km}$ and have here been interpolated to the common polar stereographic grid. Unfortunately, at the time of writing there are big gaps in the data set, hence data for the Arctic region is only available from November 2007 to April 2008 and for 2009.

ERA-Interim is a re-analysis of meteorological observations produced by the European Centre for Medium-Range Weather Forecasts (ECMWF) (Simmons et al., 2006). As in weather-forecast models, data assimilation comprises a sequence of analysis steps in which modeled background information for a short period is combined with observations to produce an optimal estimate of the state of the atmosphere at a particular time. In ERA-Interim clouds are modeled quantities, described by prognostic equations for the cloud liquid water/ice and cloud fraction, which are only indirectly constrained by the available observations of temperature, humidity etc. (Tiedtke, 1993).

To gain further insights into the cloud occurrence over the Arctic Ocean we use ground-based lidar and radar observations from the Surface Heat Budget of the Arctic Ocean project (SHEBA) (Uttal et al., 2002). The SHEBA field campaign took place from 1997 to 1998, and was aimed at understanding the ocean-ice-atmosphere coupling in the Arctic. The measurements were carried out on a floating ice sheet in the Beaufort Sea between $70^{\circ} \mathrm{N}$ and $80^{\circ} \mathrm{N}$ and $140^{\circ} \mathrm{W}$ and $170^{\circ} \mathrm{W}$. Monthly mean cloud fraction has been calculated from a 10-min averaged combined dataset (Intrieri et al., 2002b). We here emphasize that this is slightly different from the usual definition of cloud fraction. The percentage of 10 min time intervals within one month when either the lidar, or radar, observed a cloud is likely to provide an overestimate of cloud fraction, although this is a minor issue for stratiform clouds. 
Beside the modification for the surface albedo in the 2BFLXHR data set we do not implement any changes in our analysis but use the data sets as they are. By doing this the strengths and weaknesses of the three data sources remain more evident. Applying satellite simulators or modify the data in any other way would if anything obliterate the differences that are important to gain deeper knowledge from any comparison. The reader, however, should keep in mind that the data sets do not only differ in their cloud detection technique but cloud definition and the spatial and temporal sampling may contribute to any discrepancy.

\section{Arctic cloud cover}

The yearly cycles of monthly mean total and low-level cloud fraction over the Arctic Ocean from the three datasets are shown in Fig. 2. In summer months, from May until September, the passive and active satellite instrument cloud fraction estimates agree surprisingly well, with slightly (5-10\%) lower cloud fractions retrieved by AVHRR. Both retrievals show a relative minimum of cloudiness in July. They both exhibit a seasonal cycle with more cloudiness in summer and autumn, relative to winter and early spring. In the polar winter, however, the passive satellites detect far less clouds than the active satellites, down to half the cloud fraction in the midst of winter in December and January. ERA-Interim exhibits a relatively weak annual cycle, with a minimum in June, and values varying between 80 and 95 percent total cloud cover. The low-level clouds differ even more between ERA-Interim and the active satellite estimate, with nearly two times the cloud fraction in the reanalysis. In ERAInterim, the variability in low-level clouds seems to dominate the - small - seasonal cycle in total cloudiness. This is only to some extent found for the CloudSat/CALIPSO retrievals. In these, the maxima in May and October, and the local minimum in July, are obviously due to the low-level cloudiness, but the general increase from winter to autumn, and decrease thereafter, is not seen in the low-level cloudiness. Year-toyear variability within the individual datasets is surprisingly small, giving us some hope that the short records available provide useful climatological information, while understanding the underlying causes for the large discrepancies between the datasets seems crucial.

The geographical cloud fraction distributions for the year 2009 in the three datasets reveal further points of systematic agreement and differences (Fig. 3). Arguably, the best agreement between the datasets across all seasons is found over the open ocean in the North Atlantic, where all datasets show 8090 percent cloud fraction with only weak seasonal cycles. In the summer season when the datasets agree best overall, there is a tendency for ERA-Interim to show more clouds over the sea ice in the Beaufort Sea, while Cloudsat/CALIPSO systematically detects the most clouds over land of the three. In the North Atlantic sector during the coldest seasons, win-

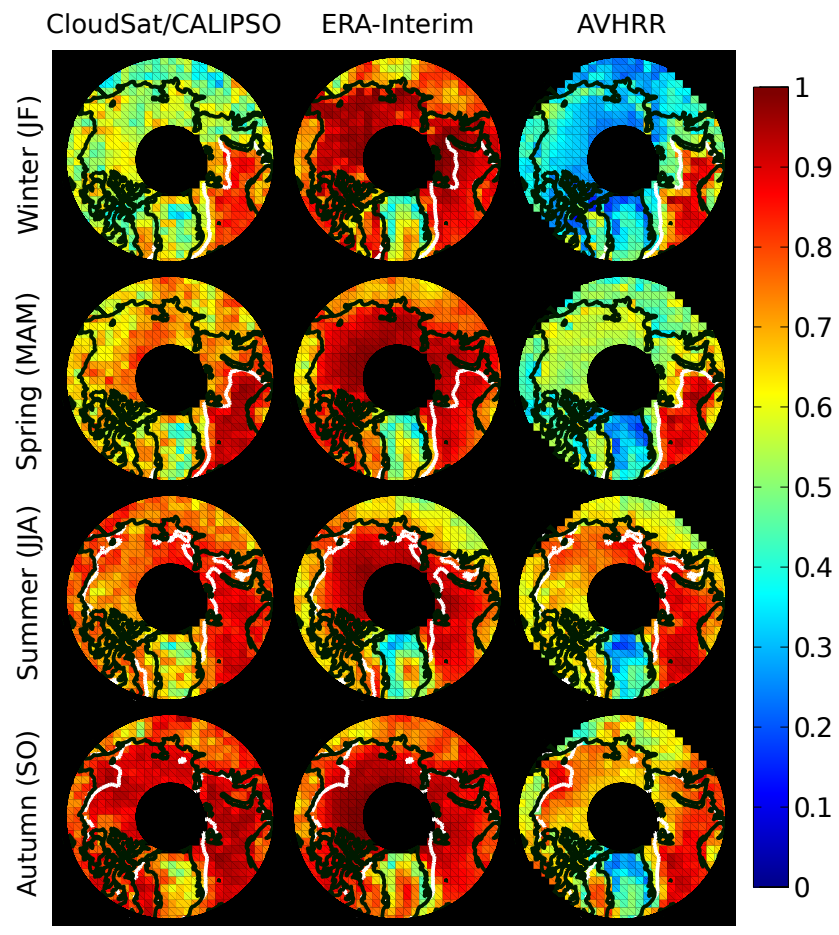

Fig. 3. Geographical distribution of seasonal mean total cloud fraction based on the merged CloudSat/CALIPSO data, for ERAInterim Reanalysis data and for CM-SAF for 2009. Values for winter are averaged over January and February and autumn only for September and October. The white line indicates the sea ice margin in the four seasons as derived from SSM/I satellite data.

ter and spring, CloudSat/CALIPSO shows significantly less clouds over sea ice than open ocean, while ERA-Interim exhibits slightly more cloudiness over sea ice relative to the open ocean.

The strong seasonal cycle in cloud fraction over the Arctic Ocean observed with the passive instrument AVHRR might be due to the lack of sunlight in the Arctic winter, effectively disabling the visible channels. Another problem could be the strengthening of the Arctic temperature inversion in the cold seasons, making it difficult to distinguish a cloud from the surface in the infra-red spectrum. The resulting bias depends on details of the algorithm used in the satellite retrieval. Evidence for these notions is found in the poleward decrease in cloud fraction in winter, spring and autumn, which is not supported by the other datasets. We cannot tell from our analysis which effect has the largest impact, however it seems very likely that the seasonal cycle observed with passive instruments is exaggerated.

Ground-based longterm cloud observations with active instruments, such as ceilometers, cloud radars and lidars, are sparse over the Arctic Ocean and is essentially limited to the SHEBA campaign from 1997 to 1998 (Intrieri et al., 2002a). Thus direct comparison with the active satellites is unfortunately presently not possible, since they were not launched 


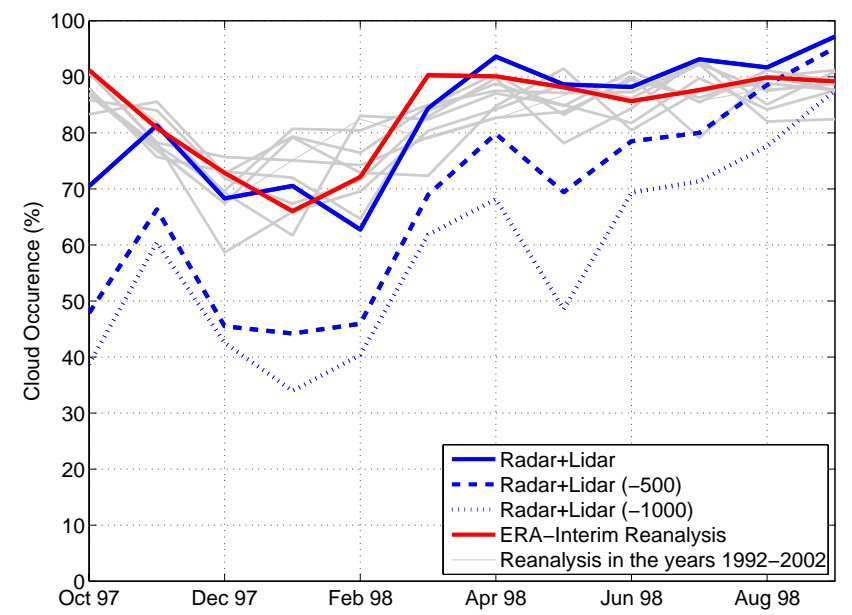

Fig. 4. Total cloud fraction based on combined ground-based lidar and radar observations (blue solid) from the SHEBA field campaign for the period from October 1997 to September 1998, while ERAInterim total cloud fraction (red solid) is averaged over the blue region shown in Fig. $1,74-81^{\circ} \mathrm{N}$ and $145-170^{\circ} \mathrm{W}$. Dashed and dotted blue lines show the total cloud fraction obtained while neglecting clouds detected in the lowest $500 \mathrm{~m}$ and $1000 \mathrm{~m}$, respectively. Gray thin lines are ten other individual years from ERA-Interim.

at that time. However, we can compare with ERA-Interim (Fig. 4). The agreement between observed cloud fraction and the reanalysis is striking, however, there are at least two caveats to this result. First, the definition of cloud fraction used in the merged radar and lidar dataset is that it is cloudy if either instrument detects a cloud in a 10-min interval. Arguably, this approach is going to inflate the result to some extent, though possibly only by a small amount in the Arctic setting which is dominated by stratus and stratocumulus clouds. The reanalysis assimilated radiosoundings carried out during SHEBA, which could potentially help ERAInterim produce a reasonable cloud cover over the region. To shed some light on the latter, we plot monthly mean cloud fractions from ten other individual years from the reanalysis. For the SHEBA-year ERA-Interim is significantly outside the multi-year ensemble only in March, and, if anything the observed summer cloud cover is about 5 percent higher than the multi-year mean from the reanalysis. These results certainly do not help explain the difference between ERAInterim and CloudSat/CALIPSO.

The Arctic skies are largely dominated by clouds in the lowest kilometer (Intrieri et al., 2002a), and these low-level clouds dominate the surface radiation budget (Shupe and Intrieri, 2004). Yet, CloudSat detects no clouds below $500 \mathrm{~m}$ and has only limited detection between 500 and $1000 \mathrm{~m}$. It is therefore of particular interest to study how these limitations potentially affect the cloud fraction estimates based on that particular instrument. We utilize the SHEBA observations to estimate the effect, by artificially removing clouds detected below these limits and then evaluate the total cloud fraction

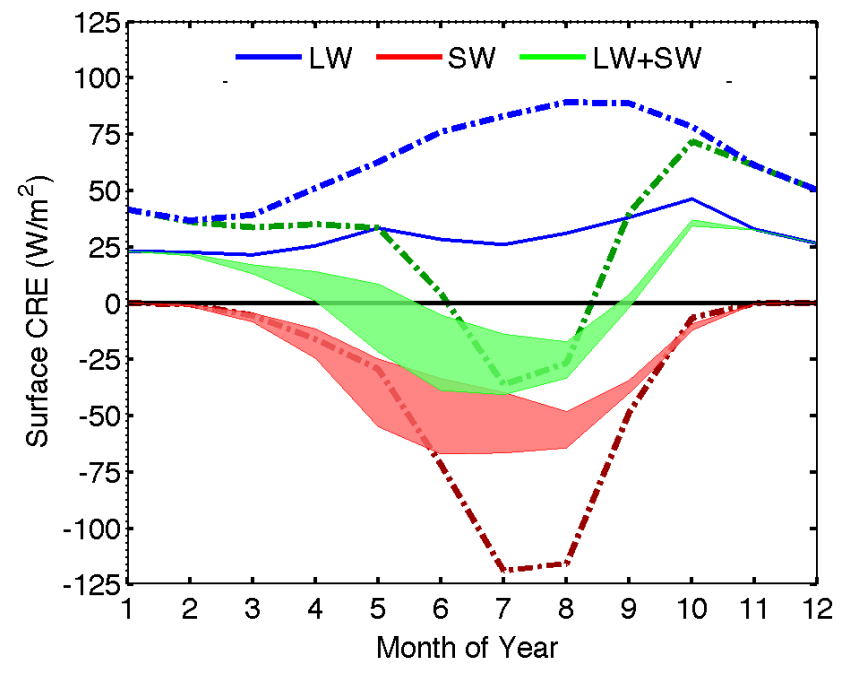

Fig. 5. Annual cycle of the long-, shortwave and net cloud radiative effects over the Arctic Ocean based on 2B-FLXHR derived from CloudSat (solid lines and areas) and on ERA-Interim (dash-dotted lines). The satellite shortwave data has been corrected for the presence of sea ice as described in the text, and the shaded areas depict the sensitivity to these choices. ERA-Interim here uses its native surface albedo, which on average is lower than the assumptions used for CloudSat.

(Fig. 4). The effect depends on season and limit, where removing all clouds below $500 \mathrm{~m}$ results in a deficit peaking at about 20 percent in winter months and around 10 percent in other months. When neglecting all clouds below $1000 \mathrm{~m}$, the deficit total cloud fraction increases further. The overall results of this sensitivity analysis do not change significantly when only considering low-level clouds below $3000 \mathrm{~m}$ (not shown).

While CloudSat has limited detection of the low-level clouds that are so common in the Arctic, CALIPSO does help correcting that particular shortcoming in the merged $2 \mathrm{~B}$ GEOPROF-LIDAR dataset. Hence, we cannot reconcile the marked discrepancy between ERA-Interim and the SHEBA climatology on the one hand, and the CloudSat/CALIPSOderived cloud fraction on the other as simply a consequence of CloudSat-shortcomings.

\section{Arctic cloud radiative effect}

Monthly means of the long- and shortwave components of the surface cloud radiative effect (CRE) from CloudSat and ERA-Interim are shown in Fig. 5. Data are again averaged over the Arctic Ocean as indicated in Fig. 1. The reader is reminded that the satellite estimates of CRE are based on CloudSat only as described in section 2, and that the shortwave component of CRE has been compensated here for the erroneous use of open ocean surface albedo where ice is present. 


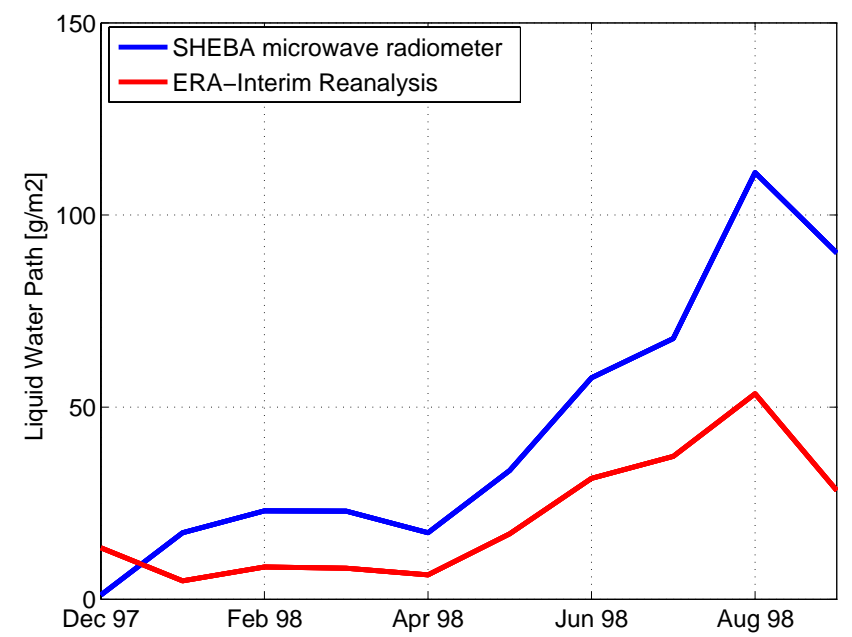

Fig. 6. Comparison of observed and ERA-Interim liquid water path with observations from a dual-channel microwave radiometer during the SHEBA campaign.

Shortwave CRE has a distinct annual cycle being near-zero in the polar-night winter and peaking in late summer in July or August when solar input is still high and sea-ice cover close to minimum. The strength in the cycle from CloudSat depends strongly on the assumed surface albedo in spring and summer as indicated by the red shading. ERA-Interim shortwave CRE agrees with CloudSat, except in July and August when the reanalysis exhibits about twice the shortwave CRE of the satellite estimate, and to some extent September with still lower values in the satellite estimate. The reanalysis uses its own surface albedo, which on average is lower than the assumed values used for CloudSat, even for the lower bound estimate. Compensating the reanalysis shortwave CRE in an analogous way to the satellite, however, reduces shortwave CRE to about $100 \mathrm{~W} \mathrm{~m}^{-2}$ in both July and August (not shown). Multiple scattering in turn, which is neglected in the CloudSat 2B-FLXHR data set, has been found to significantly increase the shortwave radiative effect (deWeaver et al., 2008).

In addition to depending on the surface albedo, shortwave CRE depends on a number of other factors, such as cloud fraction, cloud liquid water path, cloud droplet effective radius, horizontal homogeneity of the clouds, and to a lesser extent on the cloud particle phase, the Arctic background aerosol and variations in other atmospheric shortwave absorbers. Figure 6 shows a comparison of ERA-Interim average liquid water path with that observed during the SHEBA campaign using a dual-channel microwave radiometer. Interestingly, the reanalysis exhibits only around half the observed liquid water path. As we have seen before, ERAInterim cloud cover is about the same as observed, meaning that clouds in the reanalysis are thinner than indicated by the observations, which can then be ruled out as a cause for

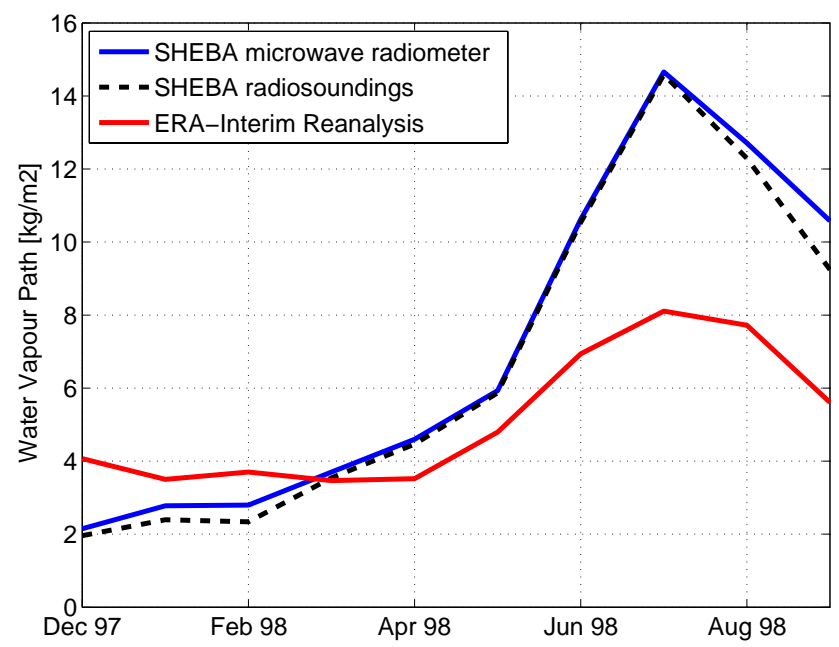

Fig. 7. Comparison of observed and ERA-Interim water vapor path with observations from a dual-channel microwave radiometer and integrated from radiosoundings during the SHEBA campaign.

the stronger shortwave CRE in ERA-Interim relative to the CloudSat estimate.

Longwave CRE differ throughout the year between CloudSat and ERA-Interim by about a factor two or more, the reanalysis exhibiting the larger values. The largest discrepancies are found in summer and early autumn. Longwave CRE at the surface depends on cloud cover, thickness, liquid droplet radius and the presence and properties of cloud ice particles, together determining their emissivity, combined with cloud height and temperature, and the background atmosphere profiles of temperature, water vapor, aerosol and greenhouse gases, together determining the radiative contrast between clear and cloudy skies.

Figure 7 compares the vertically integrated water vapor path between ERA-Interim and observations obtained from the dual-channel microwave radiometer and radiosoundings performed during the SHEBA campaign. The two measurements are found to be in very good agreement and only in the winter months a small difference can be found. Comparison to reanalysis shows a reasonable agreement in winter and spring, while in summer the reanalysis atmosphere is much drier than observed. This could explain why the longwave CRE in ERA-Interim is so strong during summer, relative to SHEBA estimates.

The available evidence is consistent with the missing lowlevel clouds by CloudSat explaining part of the discrepancies in CRE to ERA-Interim, as these clouds tend to be optically thick and warm (Shupe and Intrieri, 2004). Estimates of short- and longwave CRE from observations obtained during the SHEBA campaign are generally in between the two, albeit closer to CloudSat (Intrieri et al., 2002a). Here one needs to keep in mind that SHEBA was representative of a single ice-floe, whereas our results are averaged over the entire Arctic Ocean combining both ice and open ocean. Considering 
the difference in albedo over the ice and the ocean one would expect the true area-averaged shortwave CRE to be higher than the SHEBA-based estimates. Further it is understandable that ERA-Interim has a stronger longwave CRE in summer relative to SHEBA-based estimates because the reanalysis has is highly dry-biased.

\section{Summary and Conclusions}

Clouds play a central role in regulating the energy balance of the Earth, and because they are so heterogeneous, regionally they help determine the character of weather and climate. At the Arctic surface they tend to be warming most of the year, shifting the surface heat budget up by 10 to $50 \mathrm{~W} \mathrm{~m}^{-2}$ from autumn until spring, while in summer they tend to be slightly cooling the surface. The warming property of Arctic clouds is due to a combination of them existing in a dry and cold environment together with a highly reflective surface and a weak solar input. The role of clouds in Arctic climate change is largely unknown. Yet, we know so little about something as basic as their abundance; the disagreement in the seasonal cycle and geographical distribution among the three datasets we analyzed is striking:

1. Our results show that even active satellite instruments have trouble detecting clouds in the Arctic environment. For example, CloudSat and CALIPSO have problems detecting the low-level cloud cover in the first 500-1000 m. Ground-based measurements, using similar radars and lidars however pointed upwards, show higher total cloudiness and reveal the dominance of lowlevel clouds in the central Arctic Ocean (Intrieri et al. 2002b), which is not captured by the satellite borne instruments. Our comparison to ground based radar and lidar measurements from SHEBA shows that neglecting clouds in the lowest $500 \mathrm{~m}$ results in a underestimation of cloud occurrence of about 20 percent in winter and percent in summer.

2. In summer passive instrument CM-SAF satellite retrievals agree surprisingly well with the active instruments, with cloud fractions only slightly lower by 5 10 percent. In late autumn until early spring, when the sun is below the horizon most of the time, retrievals based on passive instrument AVHRR satellites clearly fail to detect clouds sufficiently. This is evident from the seasonal cycle and the apparently artificial southward gradient of cloud fraction over sea-ice in autumn and spring. The under-detection of the passive satellite retrievals is not too surprising as some of the used spectral channels are in the visible range, hampered by the lack of sunlight, while the infrared retrievals are difficult due to small differences between cloud and surface temperatures and the semi-persistent Arctic temperature inversions.
3. The total cloud cover produced by the ERA-Interim reanalysis model agrees surprisingly well in direct comparison to the SHEBA observation. One could suspect that the reanalysis was aided by observations from radiosondes launched during the SHEBA campaign which were likely assimilated into ERA-Interim. However, the SHEBA-year was found to be insignificantly different from other years in the reanalysis, and if anything the observed cloud cover during SHEBA is slightly above ERA-Interim.

It is important to remember that all observed differences are not only a result of different cloud detection techniques but a combination of differences in cloud detection, the temporal and spatial sampling and, more important the cloud definition. This might in particular become crucial in the summer season when differences of only 5-10 percent in cloud fraction can be observed.

Surface cloud radiative effects (CRE) estimated from CloudSat (not including CALIPSO) and ERA-Interim disagree roughly by a factor two in the individual longwave and shortwave components, while in the net these differences tend to compensate to some extent during summer months. Cloud radiative effect estimates depend on a large number of quantities and assumptions concerning properties of both the clouds themselves and their environment. While the active instrument CloudSat derived estimate - after compensation for the clearly erroneous surface albedo assumption of open water everywhere - appears to be closer to previous estimates from the SHEBA campaign than is ERA-Interim, this may well be a fortuitous result of compensating errors and lack of representability of the SHEBA observations:

1. We show that ERA-Interim has a strong dry-bias in summer having only slightly more than half the observed vertically integrated water vapor path than SHEBA. This bias would favor a stronger longwave CRE because the contrast between cloudy and clear skies is enhanced in the infrared, and indeed ERAInterim shows stronger summer longwave CRE than previously observed (Intrieri et al., 2002b; Sedlar et al., 2010).

2. While the shortwave CRE observed during SHEBA is between, but closer to CloudSat than ERA-Interim, it seems plausible that the Arctic Ocean area-average shortwave CRE over a mixture of ice and open water should be larger than the estimate from SHEBA which was on an ice-floe.

3. Neglecting multiple scattering in the 2B-FLXHR dataset results in an underestimation of the shortwave CRE. While the magnitude of this effect remains uncertain, it provides more credibility to ERA-Interim.

In all three cases the results are consistent with the fact that CloudSat cannot detect clouds below $500 \mathrm{~m}$, although 
one cannot rule out influences from assumptions made on cloud optical properties in both datasets.

The presented results have important implications for studies of trends and interactions among clouds and Arctic climate. ERA-Interim and the AVHRR based data set are popular choices for this purpose and the release of the CloudSatCALIPSO based data sets has been eagerly awaited. All three, however, have their strengths and weaknesses. Clearly, passive instrument based retrievals serve only limited purpose in anything but summer months, while they do offer by far the longest satellite records. Similar results to that presented in this paper have also been found by Karlsson and Dybbroe (2010). Recent studies indicate, however, that trends derived from some of these retrievals are suspicious (Eastman and Warren, 2010). CloudSats inability to detect low-level clouds is particularly problematic in the Arctic, as most of the clouds occur very close to the surface, and it may well bias studies if for example synoptic scale motion (subsidence or convergence) or the varying lower boundary conditions (ice or open ocean) favors one cloud regime over another leading to spurious results (Cuzzone and Vavrus, 2011). To retrieve accurate radiative fluxes, not only these low-level clouds needs to be considered, but multiple scattering, varying values for the surface albedo and variable solar zenith angle need to be implemented. On the other hand, active satellite instruments offer unprecedented capabilities to observe many aspects of clouds, in particular during the polar night. Finally, the reanalysis are attractive in that they offer a complete and long-term dataset, incorporating practically all available conventional observations. Yet, they often suffer from considerable biases and spurious jumps associated with changes in the observational system, and maybe most important: Their clouds are entirely modeled entities, which are only indirectly constrained by observations. The observed differences between the modeled clouds in ERAInterim and the two satellite retrievals are therefore not surprising. However, accounting for the dry bias in ERA-Interim and the multiple scattering in the CloudSat-CALISPO data set might significantly reduce the differences.

As a final remark we want to mention that two of the satellite data sets will be updated in 2012. For the CMSAF data set calibration corrections will be applied for the AVHRR which will improve the performance. Further a new 2BFLXHR-LIDAR data set will be released including lidar observations and variable surface albedo. However some of the main issues such as the limitation to the summer months for the AVHRR and the underestimation of low-level clouds by CloudSat-CALIPSO will remain.

Acknowledgements. The authors are thankful to Janet Intrieri and Matthew Shupe for providing the radar and lidar data from the SHEBA project and to Mark Zagar and Michael Tjernström for providing the quality controlled SHEBA radiosoundings. We acknowledge the CloudSat project for providing the CloudSat and CALIPSO data. The AVHRR were provided by the Satellite Appli- cation Facility on Climate Monitoring program. The ERA-Interim Reanalysis data was obtained from the The European Centre for Medium-Range Weather Forecasts. SSM/I was provided by Centre ERS d'Archivage et de Traitement - French ERS Processing and Archiving Facility of the French Research Institute for Exploitation of the Sea. This work was funded by Max Planck Association, and by the German Research Foundation (DFG). We thank the reviewers and the editor for their critical suggestions.

The service charges for this open access publication have been covered by the Max Planck Society.

Edited by: S. Buehler

\section{References}

Abbot, D. S., Walker, C. C., and Tziperman, E.: Can a convective cloud feedback help to eliminate winter sea ice at high $\mathrm{CO}_{2}$ concentrations?, J. Clim., 22, 5719-5731, 2009.

Arctic Climate Impact Assessment (ACIA), Cambridge University Press, 1042 pp., 2005.

Curry, J. A.: On the formation of continental polar air, J. Atmos. Sci., 40, 2279-2292, 1983.

Curry, J. A. and Herman, G. F.: Infrared radiative properties of Arctic stratus clouds, J. Clim. Appl. Meteorol., 24, 525-538, 1985.

Curry, J. A., Rossow, W. B., Randall, D., and Schramm, J. L.: Overview of Arctic cloud and radiation characteristics, J. Clim. 9, 1731-1763, 1996.

Cuzzone, J. and Vavrus, S.: The relationships between Arctic sea ice and cloud-related variables in the ERA-Interim reanalysis and CCSM3, Environ. Res. Lett., 6, 014016, doi:10.1088/17489326/6/1/014016, 2011.

DeWeaver, E. T., Hunke, E. C., Holland, M. M.: Comment on "On the reliability of simulated Arctic sea ice in global climate models" by I. Eisenman, N. Untersteiner, and JS Wettlaufer. Geophys. Res. Lett, 35, L04501, doi:10.1029/2007GL031325, 2008.

Dybbroe, A., Karlsson, K., and Thoss, A.: NWCSAF AVHRR cloud detection and analysis using dynamic thresholds and radiative transfer modeling. Part I: Algorithm description, J. Appl. Meteorol., 44, 39-54, 2005.

Eastman, R. and Warren, S. G.: Arctic cloud changes from surface and satellite observations, J. Clim. 23, 4233-4242, 2010.

Garrett, T. J. and Zhao, C.: Increased Arctic cloud longwave emmisivity associated with pollution from mid-latitudes, Nature, 440, 787-789, 2006.

Gillett, N. P., Stone, D. A., Stott, P. A., Nozawa, T., Karpechko, A. Y., Hegerl, G. C., Wehner, M. F., and Jones, P. D.: Attribution of polar warming to human influence, Nat. Geosci. 1, 750-754 (2008).

Graversen, R. G., Mauritsen, T., Tjernström, M., Källén, E., and Svensson, G.: Vertical structure of recent Arctic warming, Nature, 451, 53-56, 2008.

Held, I. M.: The tropospheric lapse rate and climate sensitivity: Experiments with a two-layer atmospheric model, J. Atmos. Sci., 35, 2083-2098, 1979.

Herman, G. F. and Goody, R.: Formation and persistence of summertime Arctic stratus clouds, J. Atmos. Sci. 33, 1537-1553, 1976. 
Holland, M. M. and Bitz, C. M.: Polar amplification of climate change in coupled models, Clim. Dynam. 21, 221-232, 2003.

Huschke, R. E.: Arctic cloud statistics from "Air-Calibrated" surface weather observations. Rand Corp. Memo., RM-6173-PR, Santa Monica, California, 79 pp., 1969.

Intrieri, J. M., Fairall, C. W., Shupe, M. D., Persson, P. O. G., Andreas, E. L., Guest, P. S., and Moritz, R. E. An annual cycle of Arctic surface cloud forcing at SHEBA. J. Geophys. Res. 107, 8039, doi:10.1029/2000JC000439, 2002a.

Intrieri, J. M., Shupe, M. D., Uttal, T., and McCarthy, B. J. An annual cycle of Arctic cloud characteristics observed by radar and lidar at SHEBA. J. Geophys. Res. 107, 8030, doi:10.1029/2000JC000423, 2002b.

Kahl, J. D. W., Martinez, D. A., Zaitseva, N. A.: Long-term variability in the low-level inversion layer over the Arctic Ocean. Int. J. Clim., 16, 1297-1313, 1996.

Kaleschke, L., Lüpkes, C., Vihma, T., Haarpaintner, J., Bochert, A., Hartmann, J., Heygster, G. SSM/I sea ice remote sensing for mesoscale ocean-atmosphere interaction analysis, Can. J. Remote Sens., 27, 526-537, 2001.

Karlsson, J. and Svensson, G. The simulation of Arctic clouds and their influence on winter surface temperature in present-day climate in the CMIP3 multi-model dataset, Clim. Dynam. 36, 623635, doi:10.1007/s00382-010-0758-6, 2011.

Karlsson, K.-G. and Dybbroe, A.: Evaluation of Arctic cloud products from the EUMETSAT Climate Monitoring Satellite Application Facility based on CALIPSO-CALIOP observations, Atmos. Chem. Phys., 10, 1789-1807, doi:10.5194/acp-10-17892010, 2010.

Kaspar, F, Hollmann, R., Lockhoff, M., Karlsson, K.-G., Dybbroe, A., Fuchs, P., Selbach, N., Stein, D., and Schulz, J.: Operational generation of AVHRR-based cloud products for Europe and the Arctic at EUMETSATs Satellite Application Facility on Climate Monitoring (CM-SAF), Adv. Sci. Res. 3, 45-51, 2009.

Kay, J. E., L'Ecuyer, T., Gettelman, A., Stephens, G., and O'Dell, C.: The contribution of cloud and radiation anomalies to the 2007 Arctic sea ice minimum, Geophys. Res. Lett., 35, L08503. doi:10.1029/2008GL033451, 2008.

Kay, J. E. and Gettelman, A.: Cloud influence on and response to seasonal Arctic sea ice loss. J. Geophys. Res. 114, D18204, doi:10.1029/2009JD011773, 2009.

L'Ecuyer, T. S.: Level 2 Fluxes and Heating Rates Product, Process Description and Interface Control Document, Version 5.1. Cooperative Institute for Research in the Atmosphere, Colorado State University, available at http://cloudsat.cira.colostate.edu/ ICD/2B-FLXHR/2B-FLXHR_PDICD_5.1.pdf, 2007.

L'Ecuyer, T. S., Wood, N. B., Haladay, T., Stephens, G. L., and Stackhouse, P. W.: Impact of clouds on atmospheric heating based on the R04 CloudSat fluxes and heating rates data set. J. Geophys. Res., 113, D00A15, doi:10.1029/2008JD009951, 2008.

Lubin, D. and Vogelmann, A. M.: A climatologically significant aerosol longwave indirect effect in the Arctic, Nature, 439, 453456, 2006.

Mace, G.: Level 2 Radar-Lidar Geoprof Product, Process Description and Interface Control Document, Version 0 - Draft, California Institute of Technology, Pasadena, California, USA, 2003.

Mace, G.: A NASA Earth System Science Pathfinder Mission, CloudSat Standard data Products Handbook. Cooperative Insti- tute for Research in the Atmosphere, Colorado State University, USA, 2008.

Manabe, S. and Wetherald, R. T.: The effects of doubling the $\mathrm{CO}_{2}$ concentration on the climate of a general circulation model, J. Atmos. Sci., 32, 3-15, 1975.

Manabe, S. and Wetherald, R. T. On the distribution of climate change resulting from an increase in $\mathrm{CO}_{2}$ content of the atmosphere. J. Atmos. Sci., 37, 99-118 (1980).

Marchand, R., Mace, G., Ackerman, T. and Stephens, G.: Hydrometeor detection using Cloudsat - An earth-orbiting 94-GHz cloud radar, J. Atmos. Ocean. Technol., 25, 519-533, 2008.

Mauritsen, T., Sedlar, J., Tjernströ m, M., Leck, C., Martin, M., Shupe, M., Sjogren, S., Sierau, B., Persson, P. O. G., Brooks, I. M., and Swietlicki, E.: An Arctic CCN-limited cloud-aerosol regime. Atmos. Chem. Phys. 11, 165-173, doi:10.5194/acp-11165-2011, 2011.

Min, S. K., Zhang, X., Zwiers, F. W., and Agnew, T.: Human influence on Arctic sea ice detectable from early 1990s onwards, Geophys. Res. Lett., 35, L21701, doi:10.1029/2008GL035725, 2008.

Partain, P.: CloudSat Project, A NASA Earth System Science Pathfinder Mission, CloudSat ECMWF-AUX Auxillary Data, Process Description and Interface Control Document, Version 3.0. Cooperative Institute for Reasearch in the Atmosphere, Colorado State University, USA, 2004.

Ramanathan, V.: Interactions between ice-albedo, lapse-rate and cloud-top feedbacks: An analysis of the nonlinear response of a GCM climate model. J. Atmos. Sci., 34, 1885-1897, 1977.

Ramanathan, V., Cess, R. D., Harrison, E. F., Minnis, P., Barkstrom, B. R., Ahmed, E., and Hartmann, D.: Cloud-radiative forcing and climate: Results from the Earth Radiation Budget Experiment, Science, 243, 57-63, 1989.

Schneider, S. H.: Cloudiness as a global climatic feedback mechanism: The effects on the radiation balance and surface temperature of variations in cloudiness, J. Atmos. Sci., 29, 1413-1422, 1972.

Schweiger, A. J. and Key, J. R.: Arctic Cloudiness: Comparison of ISCCP-C2 and Nimbus-7 satellite derived cloud products with a surface based on cloud climatology, J. Clim., 5, 1514-1527, 1992.

Sedlar, J., Tjernström, M., Mauritsen, T., Shupe, M. D., Brooks, I. M., Persson, P. O. G., Birch, C. E., Leck, C., Sirevaag, A., and Nicolaus, M.: A transitioning Arctic surface energy budget: the impacts of solar zenith angle, surface albedo and cloud radiative forcing, Clim. Dynam. 37, 1643-1660, doi:10.1007/s00382-0100937-5, 2010.

Serreze, M. C. and Francis, J.: The Arctic amplification debate, Clim. Change, 76, 241-264, 2006.

Serreze, M. C., Holland, M. M. and Stroeve, J.: Perspectives on the Arctic's rapidly shrinking sea-ice cover, Science, 315, 15331536, 2007.

Shupe, M. and Intrieri, J.: Cloud radiative forcing of the arctic surface: The influence of cloud properties, surface albedo and solar zenith angle, J. Clim. 17, 616-628, 2004.

Simmons, A., Uppala, S., Dee, D. and Kobayashi, S.: ERA-Interim: new ECMWF reanalysis products from 1989 onwards. ECMWF Newslett., 110, 25-35, 2006.

Soden, B. J. and Vecchi, G. A. The vertical distribution of cloud feedback in coupled ocean-atmosphere models. Geophys. Res. 
Lett. 38, L12704, doi:10.1029/2011GL047632, 2011.

Solomon, S., Qin, D., Manning, M., Chen, Z., Marquis, M., Averyt, K. B., Tignor, M., and Miller, H. L.: Climate change 2007: The physical science basis, Cambridge University Press, 996 pp. (2007).

Stephens, G. L., Vane, D. G., Boain, R. J., Mace, G. G., Sassen, K., Wang, Z., Illingworth, A. J., O'Connor, E. J., Rossow, W. B., Durden, S. L., Miller, S. D., Austin, R. T., Benedetti, A., Mirescu C., and the CloudSat Team: The CloudSat mission and the ATrain, B. Am. Meteor. Soc. 83, 1771-1790, doi:10.1175/BAMS83-12-1771, 2002.

Stephens, G. L., Vane, D. G., Tanelli, S., Im, E., Durden, S., Rokey, M., Reinke, D., Partain, P., Mace, G.G., Austin, R. T., L'Ecuyer, T. S., Haynes, J., Lebsock, M., Suzuki, K., Waliser, D., Wu, D. Kay, J., Gettelman, A., Wang, Z., and Marchand, V.: CloudSat mission: Performance and early science after the first year of operation, J. Geophys. Res, 113, D00A18, doi:10.1029/2008JD009982, 2008.

Stroeve, J., Holland, M. M., Meier, W., Scambos, T., and Serreze, M.: Arctic sea ice decline: Faster than forecast. Geophys. Res. Lett. 34, L09501, doi:10.1029/2007GL029703, 2007.
Tiedtke, M.: Representation of clouds in large-scale models Monthly Weather Review, 121, 3040-3061, 1993.

Uttal, T., Curry, J. A. , McPhee, M. G., Perovich, D. K., Moritz, R. E., Maslanik, J. A., Guest, P. S., Stern, H. L., Moore, J. A., Turenne, R., Heiberg, A., Serreze, M. C., Wylie, D. P., Persson, P. O. G., Paulson, C. A., Halle, C., Morrison, J. H., Wheeler P. A., Makshtas, A., Welch H., Shupe, M. D., Intrieri J. M., Stamnes K., Lindsey R. W., Pinkel, R., Pegau, W. S., Stanton, T. P., and Grenfeld T. C.: Surface heat budget of the Arctic ocean. B. Am. Meteor. Soc., 83, 255-275, 2002.

Vavrus, S., Holland, M. M., and Bailey, D. A.: Changes in Arctic clouds during intervals of rapid sea ice loss, Clim. Dynam. 36, 1475-1489, doi:10.1007/s00382-010-0816-0, 2011.

Walsh, J. E. and Chapman, W. L.: Arctic cloud-radiationtemperature associations in observational data and atmospheric reanalysis, J. Clim., 11, 3030-3045, 1998.

Winker, D., Hund, W. H., and Gill, M. C.: Initial performance assessment of CALIOP, Geophys. Res. Lett., 34, L19803, doi:10.1029/2007GL030135, 2007.

Wetherald, R. T. and Manabe, S.: Cloud feedback processes in a general circulation model, J. Atmos. Sci., 45, 1397-1415, 1988. 